\title{
Habitat preferences and interannual variability in occurrence of the harbour porpoise Phocoena phocoena off northwest Scotland
}

\author{
Francesca Marubini $^{1, *}$, Alessandro Gimona ${ }^{2}$, Peter G. H. Evans ${ }^{3}$, Peter J. Wright ${ }^{4}$, \\ Graham J. Pierce ${ }^{1,5}$ \\ ${ }^{1}$ School of Biological Sciences (Zoology), University of Aberdeen, Tillydrone Avenue, Aberdeen, AB24 3EX, UK \\ ${ }^{2}$ Macaulay Institute, Craigiebuckler, Aberdeen, AB15 8QH, UK \\ ${ }^{3}$ Sea Watch Foundation, 11 Jersey Road, Oxford, OX4 4RT, UK \\ ${ }^{4}$ Fisheries Research Services (FRS) Marine Laboratory, PO Box 101, 375 Victoria Road, Aberdeen, AB11 9DB, UK \\ ${ }^{5}$ Instituto Español de Oceanografía, Centro Oceanográfico de Vigo, PO Box 1552, 36200, Vigo, Spain
}

\begin{abstract}
The harbour porpoise Phocoena phocoena is the most common cetacean around the British Isles, but knowledge of its ecology, habitat preferences and inter-annual variability is still inadequate. Here, sightings collected by the Sea Watch Foundation during vessel surveys in West Scotland (August during the years 1993, 1994, 1996 and 1997) were critically analysed and used to construct a predictive habitat model for harbour porpoises in the Greater Minch. Generalised additive models were used to analyse relative abundance in relation to environmental variables; a preference for waters within $15 \mathrm{~km}$ from the shore and between 50 and $150 \mathrm{~m}$ depth was clearly identified. A relationship between tidal variables and porpoise distribution was also recognised with more sightings predicted for high tidal stream speed areas as well as during times of high tide. Maps constructed from the model were used to identify potential 'hotspots'and compare between years. Four areas with high relative abundance were identified in (1) the region between Ardnamurchan, Coll and the Small Isles, (2) southeast of Barra, (3) northeast of Skye to Gairloch, and (4) west of Pairc Peninsula (Isle of Lewis) to Shiant Islands. Number of sightings fluctuated up to 4 -fold between consecutive years; such extreme variability in relative abundance is offered as a bench-mark for comparing trends in the future as well as evidence that the Greater Minch represents only a small part of the effective range of this population.
\end{abstract}

KEY WORDS: Phocoena phocoena - Habitat preference · Relative abundance · Inter-annual variability

\section{INTRODUCTION}

Coastal waters around the British Isles are rich in cetaceans . The most common and widespread species is the smallest and most inconspicuous of them all, the harbour porpoise Phocoena phocoena; its known distribution in the Eastern Atlantic covers the shelf waters around the UK and Ireland in their entirety, extending east across the North Sea to the Baltic Sea, north to the Barents Sea, and south along the African coast to Senegal (Reid et al. 2003).

Some degree of genetic differentiation has been observed between geographical areas in the north- east Atlantic (Andersen et al. 1997, 2001, Walton 1997, Tolley et al. 2001) but on the whole, individuals observed in UK waters are considered to be part of a single continuous population ranging northwards from the French coast of the Bay of Biscay to Norway and Iceland (Fontaine et al. 2007). Within UK waters, there are 4 areas where sightings have been most concentrated over the long-term; these are the Shetland Isles, the Minch and Sea of Hebrides, southern Cardigan Bay and the north Pembrokeshire coast, and off the north Devon coast (Evans \& Wang 2002).

Harbour porpoises face a variety of anthropogenically induced threats, the single most obvious one 
being commercial fisheries. Parties to the Agreement on the Conservation of Small Cetaceans of the Baltic and North Seas (ASCOBANS) have agreed to work towards reducing by-catch levels to below $1.7 \%$ per year of the North Sea porpoise population (ASCOBANS 2000) to ensure that this species is maintained in a favourable conservation status. Robust estimates of population size are necessary to quantify the impact of by-catch; to this end the large-scale surveys known as SCANS I \& II (Small Cetacean Abundance in the North Sea) were carried out in 1994 and again in 2005, during the month of July (Hammond et al. 2002, Hammond \& Macleod 2006). In addition, different types of disturbance (e.g. noise, chemical pollutions, aquaculture) might result in temporal redistributions of animals among adjacent areas rather than changes at the population level.

For conservation measures to be most effective, greater knowledge of habitat use and habitat preference is highly desirable at a variety of spatial scales from the national to the local spatial scale, especially as spatial planning is becoming the framework for management of human activities within the marine realm (Defra 2006). Furthermore, as the harbour porpoise is on Appendix 2 of the EC Habitats Directive (Council Directive 92/43/EEC), there has been an impetus towards identifying areas able to fit the criteria required to designate Special Areas of Conservation for this species (Evans \& Wang 2002).

Habitat models are a useful tool in providing a better understanding of the ecological processes underlying cetacean distributions (Redfern et al. 2006). In UK waters, cetacean-habitat relationships are starting to be explored for Phocoena phocoena, and depth has been successfully used to explain distribution patterns (Embling 2007, MacLeod et al. 2007, Weir et al. 2007). In addition, large-scale habitat models are necessary to identify important habitat variables and to predict a species distribution pattern. It is also essential to analyse models over years to understand inter-annual variability in relative abundance. Only if the baseline is known, can trends in relative abundance over time be understood.

In this study, we aimed to construct a habitat model with a temporal component by analysing long-term datasets of harbour porpoise sightings. In the UK, Sea Watch Foundation maintains the largest database of cetacean sightings, with records dating back to the 1950s (Evans 1980, Evans et al. 2003). This database is an integral part of the Joint Cetacean Database that has been successfully used to describe species distributions around the UK (Reid et al. 2003). Further analysis of this database to study habitat preferences and trends in abundance at large geographical and temporal scales is limited by very heterogeneous platform types, modes of survey, and observers (Evans \& Hammond 2004). Nonetheless, data collected by different methods do not have to be disregarded a priori (Redfern et al. 2006), e.g. confining spatial and temporal scale can minimise heterogeneity.

Here we focus on a sub-set of the Sea Watch Foundation database consisting of summer surveys from 1993 to 1997 carried out in the Sea of Hebrides and in the North and Little Minches (NW Scotland, see Fig. 1). Quality and survey technique were consistent for these data. The area, collectively known as the Greater Minch, is outstanding in its geological and biological richness and diversity. Its complex topography with deep fjordic sea lochs and several islands and islets provides for many sea conditions (highly exposed to highly sheltered), steep gradients (e.g. depth $>240 \mathrm{~m}$ within $5 \mathrm{~km}$ from the shore in the Inner Sound) and high current speeds (Barne et al. 1997). This region is among the richest in the UK for cetaceans with 20 species recorded since 1980 (Evans 1997). Harbour porpoise Phocoena phocoena is the most common species, present throughout the year and thought to show increased occurrences during summer (Reid et al. 2003). Other common species are the minke whale Balaenoptera acutorostrata, shortbeaked common dolphin Delphinus delphis, whitebeaked dolphin Lagenorhynchus albirostris, Risso's dolphin Grampus griseus, and killer whale Orcinus orca (Evans 1997). Threats to harbour porpoises in this area includes by-catch (although to a more limited degree than in the North Sea or Celtic Sea, Northridge et al. 2003), localised disturbance from aquaculture operations, vessel traffic (including recreational activities) (Parsons et al. 1999) and the potential future development of tidal energy technology (Scottish Executive 2007).

A critical analysis of this dataset offers an ideal opportunity to model harbour porpoise distribution as a function of environmental variables and describe inter-annual variability in relative abundance in the recent past.

\section{METHODS}

Survey area and survey design. During the summers between 1992 and 1998, the Sea Watch Foundation chartered the $23 \mathrm{~m}$ sailing vessel 'Marguerite Explorer' to carry out cetacean surveys throughout the Sea of Hebrides and the Little and North Minches (NW Scotland, UK) (Fig. 1).

While Sea Watch encourages public participation in cetacean research and the scientific quality of data collected over the entire period is variable, we focused exclusively on a series of dedicated surveys led by 
experienced observers. These surveys were conducted by following pre-determined track-lines, chosen to sample the entire area in a representative manner. Overall methodology was similar to line-transect (Evans \& Hammond 2004). Transects were started only at Beaufort sea state 2 or less, but there were times during a survey when the sea state increased beyond this. Continuous watches (naked eye scans supplemented with binocular checks when a possible sighting was made) were made from the bow of the vessel using teams of 3 persons, 1 observing to portside, 1 to starboard, and 1 co-ordinating and recording observations. Each team watched for $1 \mathrm{~h}$ and rested for at least $2 \mathrm{~h}$, unless there was a sustained cetacean encounter when off-duty personnel sometimes participated in recording additional information. At regular intervals (mainly every $15 \mathrm{~min}$ ), the ship's position (measured by GPS), sea state and other environmental data such as swell height, visibility, cloud cover, and precipitation, were recorded. A sighting consisted of an event when 1 or more harbour porpoises were observed. At each sighting, the time, boat position, estimate of group size and environmental data were recorded. All details were recorded on standardised forms, and later transferred to computer. Observation height was 4 to $5 \mathrm{~m}$ above sea level, and the ship speed averaged around 7 knots.

Quality assurance analysis and GIS. To ensure consistency in time and space, survey effort for each month within each year was mapped separately and compared visually. The most consistent and extensive spatial coverage across years was obtained with the August cruises. This study focuses on all surveys carried out during 29 July to 20 Aug 1993, 30 July to 18 Aug 1994, 10 to 22 Aug 1996 and 9 to $22 \mathrm{Aug}$ 1997, as shown in Fig. 2. In 1995, cruises were carried out much earlier (only in June), and are not included in these analyses.

The database consisted of 2 parts, effort and sightings. (1) We focused on survey effort and analysed the spatial component of each survey by mapping each track segment using ArcGIS. The effort database contains coordinates and time for the beginning and end of each segment which was therefore represented by a straight line. Errors in coordinates were at times identified and, when possible, corrected by checking the original datasheets. When correction was not possible, the segment was removed from further analysis. (2) The locations of sightings were mapped over the survey tracks; the sighting database contains position and time when a sighting took place. Any inconsistency between position or time of a sighting and those

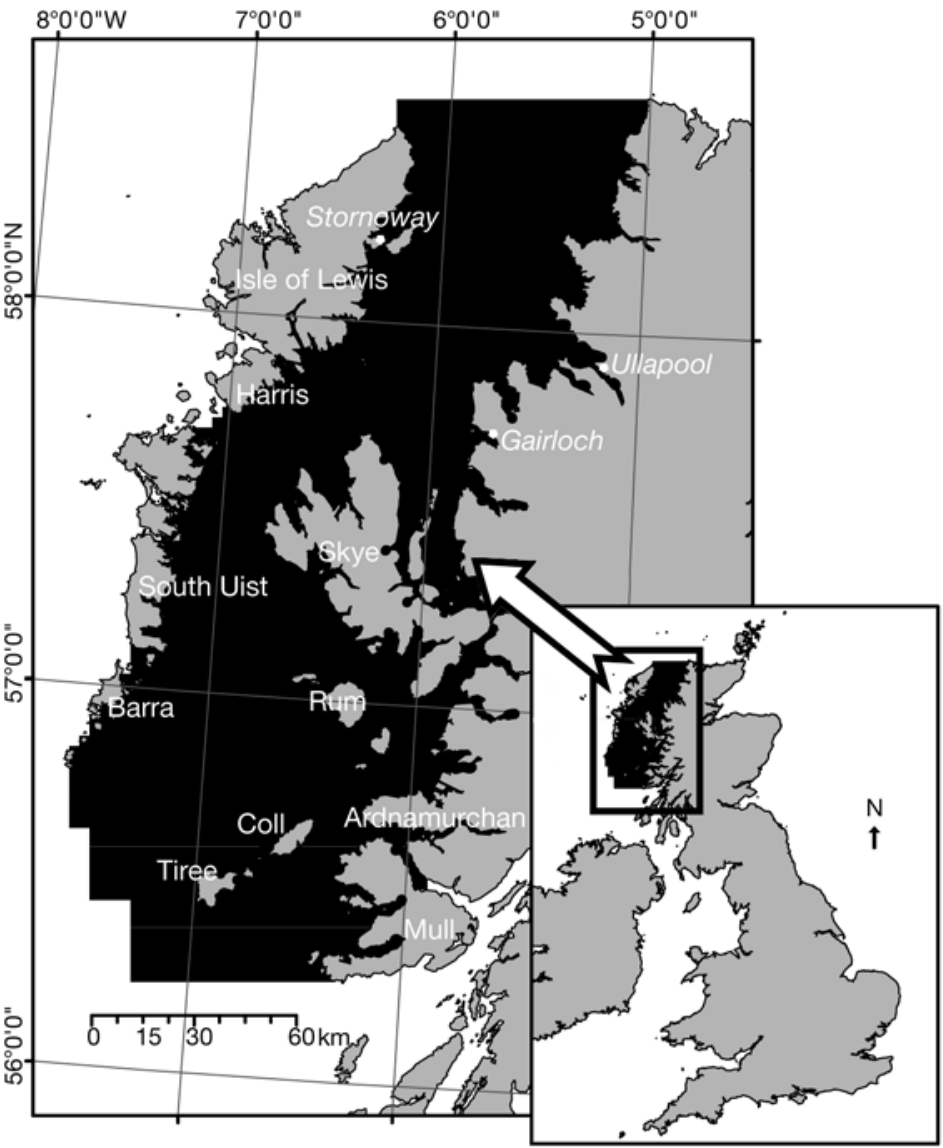

Fig. 1. Study area (black) in the Greater Minch; towns (in italics), isles and peninsulas are identified for clarity. A map of the British Isles with position of study area is also shown

of the effort segment linked to it was identified, and the associated data either corrected (where possible) or removed.

The single segment of the survey track was chosen as the unit for all further analysis. For each segment, duration (min) was calculated from the original start and end time, while length was obtained in ArcGIS as distance $(\mathrm{km})$ between start and end coordinates; thus, average boat speed was calculated $\left(\mathrm{km} \mathrm{h}^{-1}\right)$. We chose to remove outliers by accepting for analysis only those segments with a maximum duration of $60 \mathrm{~min}$, maximum length of $10 \mathrm{~km}$, and a speed during observation between 5 and $14 \mathrm{~km} \mathrm{~h}^{-1}$. These criteria resulted in the removal of 51 segments $(<3 \%$ of the total).

Environmental variables. Sea state was recorded using the Beaufort scale, and was available in the original database for each segment of the track. Sea state is known to have a strong influence on the ability of the observer to spot a cetacean (Palka 1996, Evans \& Hammond 2004); segments undertaken in Beaufort sea state above 3 were not included in the analyses and effort maps. 

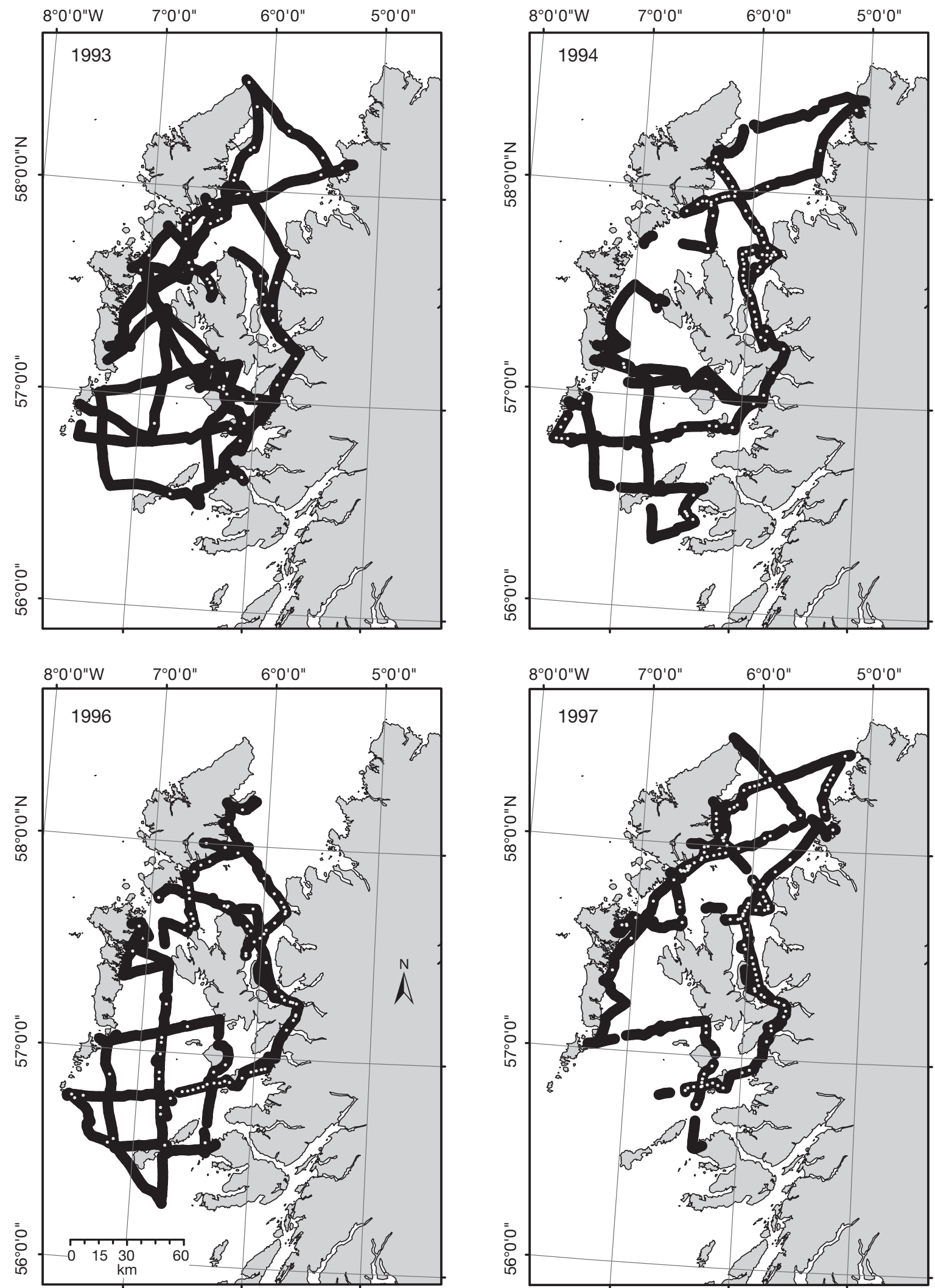

Fig. 2. Surveys carried out in August 1993, 1994, 1996 and 1997, and accepted for analysis. Sightings are marked by white circles on the survey tracks 
Topographic variables (i.e. bathymetry and distance from shore) need to be extracted in a way to best represent the original segment of effort. Observers continuously scanned an area of $180^{\circ}$ forward centred on the track-line. Therefore a segment does not just represent a line in space but an area. In ArcGIS we transformed each segment from a line to a $2 \mathrm{~km}$ wide polygon, by adding a $1 \mathrm{~km}$ wide buffer zone on both sides of the original line.

Bathymetry was obtained from the offshore digital geological map dataset (British Geological Society: DigBath-250, 1:250000). For the entire area, bathymetry was extracted for the centre point of each cell within a $0.5 \mathrm{~km}$ grid upon which survey track polygons were overlaid. Average depth per segment was calculated as the arithmetic mean of all the values within the area of the survey track polygon. If the boat was so close to shore that a $1 \mathrm{~km}$ buffering zone would encompass land, these points were removed before averaging. Standard error of depth was calculated per polygon and used as a measure of the variability in bottom topography for each cruise segment. Distance from shore was extracted for each cell within a polygon and then averaged. Tidal height (metres above extreme low tide) and tidal stream speed (knots [kn]) were obtained from the tidal prediction programme (United Kingdom Hydrographic Office: Admiralty TotalTide, version 5). In total, predictions for 40 ports and 28 streams were used to cover the whole area. Ports and streams were linked to a survey segment by spatial proximity in ArcGIS.

Model fitting. Correlations among explanatory variables were tested but found not to be significant. The number of sightings per survey segment was modelled using generalised additive models (GAMs) (Hastie \& Tibshirani 1990, Swartzman et al. 1992). A Poisson error distribution was used with a log link function to perform model selection. To account for over-dispersion due to many zero counts, the selected model was refitted using a quasi-poisson link before using it to make predictions. This strategy permitted the use of AIC in model selection (quasi-poisson models do not have a defined likelihood, while also providing better standard error estimates used in model predictions.

The explanatory variables used in the GAM were the environmental variables (depth, bottom topography, distance from shore, tide height, tidal stream speed, sea state), the temporal variable 'year' and segment quality variables (segment duration, length and speed). Categorical explanatory variables ('sea state' and 'year') were treated as factors, and since each of them consisted of 4 levels, they were coded using 3 dummy variables (Zar 1984). The coding scheme is shown in Table 1.

The first dummy variable was coded to identify a significant effect of the variable as occurring between lev-
Table 1. Coding scheme for the dummy variables used to code the variables 'sea state' and 'year' of generalised additive models

\begin{tabular}{|cccc|}
\hline \multirow{2}{*}{ Year } & \multicolumn{3}{c|}{ Dummy variables $-\mathrm{d} 2$} \\
\cline { 2 - 4 } & $\mathrm{d} 1$ & 0 & $\mathrm{~d} 3$ \\
\hline 1993 & 0 & 0 & 0 \\
1994 & 1 & 1 & 0 \\
1996 & 1 & 1 & 1 \\
1997 & 1 & & \\
\hline
\end{tabular}

els 0 and 1, the second between levels 1 and 2 and the third between levels 2 and 3 (Walter et al. 1987, Marubini \& Davies 1996). While we found this coding more flexible for our purposes, it should be noted that internal coding using the 'factor' function in $\mathrm{R}$ yielded exactly identical predictions. All continuous explanatory variables were entered as smoothers while an interaction between segment length and vessel speed was added as a bi-modal smoother to compensate for any potential effect of variability in speed and distance on porpoise detection rate.

The selection of explanatory variables to be retained in the final model was carried out using unbiased risk estimator (UBRE) scores (Craven \& Wahba 1978, Wood 2006). This approach consists of choosing smoothing parameters in such a way as to minimise the estimate of the expected mean square error of the model; this estimate is the UBRE. Following Wood \& Augustin (2002), we therefore chose to use all our data to create the model, instead of using a training and a validation set as some authors prefer, thus intrinsically increasing its power. Then, to estimate the degree of uncertainty in the predictions, we calculated the credible interval through the statistical approach proposed by Wood (2006). We further discuss this approach below.

Thin plate regression splines were used as penalised regression smoothers. These have the advantage of not requiring explicit placement of 'knots' or selecting basis functions. They were also useful in model selection because they have smoothness penalties which include a small shrinkage component, so when smoothing parameters are large enough, the smooth becomes zero. This allows automatic smoothing parameter selection methods to effectively remove the term from the model altogether (see Wood 2006 for further details). However, to avoid overfitting that could render biological parameters difficult to interpret, the maximum number of degrees of freedom was set to 4 . Complete automatic smoothing was allowed for tidal height as it might vary sinusoidally and for the bidimensional smoothers. Further checks were carried out by dropping model terms and comparing the AIC (Akaike 1973) of the different models as well as carry- 
ing out an analysis of deviance on the models to be compared.

To obtain the best possible predictive power, we tested if the best model fitted as described above could be improved by including geographical co-ordinates. Thus, a second GAM model was fitted with latitude and longitude of the centre point of each segment included as a bi-dimensional smoother. Comparison between the models with and without co-ordinates was tested using analysis of deviance. The best model was chosen for developing spatial and temporal predictions.

Since autocorrelation increases the risk for a type I error, absence of autocorrelation in residuals of both models was tested via a Monte Carlo randomisation. The coordinates of residuals were swapped randomly 999 times and, at each iteration, the experimental variogram of residuals recalculated. We were thus able to check that the points of the variogram of the original residuals were contained in the variogram envelope resulting from this randomisation. The variogram envelope was obtained by taking the 97.5 th and 2.5 th percentiles of the distribution of the 999 values obtained for each variogram lag.

Predictive mapping. Maps of modelled sightings over the entire study area were constructed in order to (1) obtain the best possible predictive map to identify areas of particular importance to this species, and (2) estimate differences in relative abundance for the whole study area between years.

To achieve the first objective, predictions were modelled for an 'ideal' moment in time on 11 August 1997 with calm sea (sea state $=0$ ) around the diurnal high neap tide (11:00 am) using mean segment qualities (length $3 \mathrm{~km}$, speed $10.5 \mathrm{~km} \mathrm{~h}^{-1}$ ). Since the survey was based on linear transects, we filled the study area with a grid of points separated by $3 \mathrm{~km}$ in the east-west direction and $2 \mathrm{~km}$ in the north-south direction; each point became the centre of a $3 \mathrm{~km}$ line, and averages of environmental variables were calculated over $1 \mathrm{~km}$ elliptical buffers around these lines. The line was chosen to be $3 \mathrm{~km}$ long, as this corresponds to the size of the average segment in the study. To test for any effect of orientation of the elliptical buffer, a grid of prediction points at $2 \times 3 \mathrm{~km}$ intervals was also used. Since no difference was obtained, we chose to present only the predictive maps based on the $3 \times 2 \mathrm{~km}$ grid. For GIS display purposes, the final map was smoothed further, using a $3 \times 3 \mathrm{~km}$ grid and calculating the values of the centre of each square cell using interpolation of the original irregular grid values.

The effect of year on the relative abundance of harbour porpoises was further explored by using the best model to predict the total number of porpoise encounters in each of the survey years, assuming constant ideal conditions (i.e. sea state $=0$ and during diurnal high neap tide). Uncertainty of prediction estimates for the mean in both the spatial and temporal predictions was calculated using the approach suggested by Wood (2006). This is based on using the underlying parametric representation of GAMs to obtain the predictor matrix relating the model parameters to the predictions of the linear predictor. Variance estimates were derived by simulating 999 replicate parameter sets from the posterior distribution of the vector of model parameters. These, in conjunction with the prediction matrix, were used to obtain 999 replicates of predictions as well as the upper and lower extremes of the credible interval (i.e. the 97.5 and 2.5 percentiles obtained for each predicted location).

\section{RESULTS}

\section{Summary of survey characteristics}

In total, 1875 segments were included in this analysis, corresponding to $541 \mathrm{~h}$ of effort. A total of 649 sightings, comprising 1223 harbour porpoises, were recorded (average of 1.88 ind. per sighting). Quantity and quality of effort during each survey year is summarized in Table 2, together with the number of sightings. Total annual effort ranged from 426 survey segments in 1994 to 507 segments in 1996. The dataset included segments ranging from 2 to $60 \mathrm{~min}$ in duration and from 0.3 to $9.9 \mathrm{~km}$ in length. The great majority of segments were found to be much more consistent in space and time. The average segment lasted $17( \pm 7.7) \mathrm{min}$ and was 3 $( \pm 1.5) \mathrm{km}$ long. With the exception of surveys carried out in 1993, a frequency distribution of segment duration showed a marked peak around $15 \mathrm{~min}$ duration with 54,69 and $86 \%$ of all segments lasting between 13 and $17 \mathrm{~min}$ in 1994, 1996 and 1997, respectively. In 1993 observations must have focused on both 15 and $30 \mathrm{~min}$ transects and this is reflected in the presence of 2 peaks in frequency distribution: the first one around 15 min (23\% segments between 13 and $17 \mathrm{~min}$ ) and the second around $30 \mathrm{mins}$ (33\% segments between 28 and $32 \mathrm{~min}$ ). A similar pattern is true when length is analysed: a more scale-consistent subset corresponding to segments with length equal to the average $\pm 1 \mathrm{SD}$. (i.e. ranging from 1.5 to $4.5 \mathrm{~km}$ ) includes $49 \%$ of the data in 1993 but as much as 78, 80 and $82 \%$ in 1994, 1996 and 1997, respectively.

Sea state varied between 0 (optimal calm conditions) and 3 (large wavelets, crests begin to break, some whitecaps) in all years (Table 2). Optimal calm condi- 
tions were encountered during one third ( 27 to $35 \%$ ) of the survey segments for each year. Seastate 1 was more commonly encountered in 1993 and 1997 (36 and $38 \%$ ) than in 1994 and 1995 (20 and 24\%) when a higher proportion of segments was observed with seastate 2. Seastate 3 was encountered rarely in all years, accounting only for 5 to $12 \%$ of all segments.

All environmental variables showed a strong consistency between years and in all cases varied less between years than within years. Plots of environmental variables against segment length showed a random scatter of points in all cases thus suggesting no specific bias having been introduced through variable segment size.

Coverage of the study area was obtained by crisscrossing the Greater Minch several times; spatial coverage and actual position of sightings can be compared between years in Fig. 2. While surveys in 1993 and 1994 covered the entire study area, in 1996 the boat did not reach the northeastern part of the Minch and in 1997 the southern part of the Sea of Hebrides was omitted. The number of sightings per segment ranged between 0.13 in 1993 and 0.55 in 1997.

\section{Modelling relative abundance of harbour porpoises}

The minimum adequate GAM (Model a in Table 3) succeeded in explaining $29.5 \%$ of deviance. Residuals were tested for spatial autocorrelation but none was present. Segment duration and bottom topography were the only explanatory variables to be removed as their effect was not significant.

The number of sightings was significantly reduced as seastate increased from 0 to 1 (coefficient -0.7) and again from 1 to 2 (coefficient -0.9); further decrease between seastate 2 and 3 was not significant.
The variable 'year' was also shown to have a highly significant effect on the number of sightings per survey segment; each year was significantly different from the previous one rather than a consistent trend could be established. Instead, number of sightings was low in 1993 and 1996, and high in 1994 and 1997.

The relationships between spatial predictor variables and the response are presented in Fig. 3a-d. When depth is between 50 and $150 \mathrm{~m}$, the number of sightings of harbour porpoises per survey segment is highest, with fewer sightings in shallow and very deep water. Sightings were relatively constant with distance from shore up to $10-15 \mathrm{~km}$, but they decreased very rapidly after that. Tidal height up to $4 \mathrm{~m}$ above extreme low tide had a positive linear effect on the number of sightings, but above this threshold the relationship becomes negative; the variable 'tidal stream speed' was positively related to number of sightings by a 2-step increase between 0.5 and $1 \mathrm{kn}$ and then again above $1.5 \mathrm{kn}$.

The effect of bi-dimensional smoother of length and vessel speed was significant pointing to significant variability in detection rate introduced by variable segment qualities. In light of the potential issues introduced by working on variable segment size and in particular the possibility that the use of multiple scales might confuse habitat preference models, the results of this model on the entire dataset were compared with those from a GAM carried out on a size consistent subset of segments. The sub-set included only segments between 1.5 and $4.5 \mathrm{~km}$ long (e.g. average segment length $\pm 1 \mathrm{SD}$ ) and its consistency was recognised in the model as none of the segment quality variables (duration, length and speed) were any longer significant. The results were very similar both in the level of significance and in the shape of the relationship between environmental variables and number of sightings; indeed the only difference was that bottom topography was also found to be significant.

Table 2. Phocoena phocoena. Comparison of the effort qualities, environmental characteristics and number of sightings between years. Data are counts for 'Survey segments', percentage of segments in each Beaufort sea state; means and range for all other variables

\begin{tabular}{|c|c|c|c|c|c|c|c|c|c|c|c|c|c|}
\hline \multirow[t]{2}{*}{ Year } & \multirow{2}{*}{$\begin{array}{l}\text { Survey } \\
\text { segments } \\
\text { (n) }\end{array}$} & \multirow[t]{2}{*}{$\begin{array}{l}\text { Duration } \\
\text { (min) }\end{array}$} & \multirow[t]{2}{*}{$\begin{array}{l}\text { Length } \\
(\mathrm{km})\end{array}$} & \multirow[t]{2}{*}{$\begin{array}{l}\text { Depth } \\
\text { (m) }\end{array}$} & \multirow{2}{*}{$\begin{array}{c}\text { Bottom } \\
\text { topography } \\
(\mathrm{m})\end{array}$} & \multirow{2}{*}{$\begin{array}{l}\text { Distance } \\
\text { from } \\
\text { shore }(\mathrm{km})\end{array}$} & \multirow{2}{*}{$\begin{array}{l}\text { Tide } \\
\text { height } \\
\text { (m) }\end{array}$} & \multirow{2}{*}{$\begin{array}{c}\text { Tidal } \\
\text { stream } \\
\text { speed }(\mathrm{kn})\end{array}$} & \multirow{2}{*}{$\begin{array}{c}\text { Sightings } \\
\text { per segment } \\
\text { (n) }\end{array}$} & \multicolumn{4}{|c|}{$\begin{array}{c}\text { Beaufort } \\
\text { sea state }(\%)\end{array}$} \\
\hline & & & & & & & & & & 0 & 1 & 2 & 3 \\
\hline 1993 & 474 & $\begin{array}{c}23 \\
(2-60)\end{array}$ & $\begin{array}{c}3.97 \\
(0.3-9.9)\end{array}$ & $\begin{array}{c}84 \\
(8-198)\end{array}$ & $\begin{array}{c}3.2 \\
(0-16.9)\end{array}$ & $\begin{array}{c}5.7 \\
(0.1-27.5)\end{array}$ & $\begin{array}{c}2.8 \\
(0.4-5.5)\end{array}$ & $\begin{array}{c}0.44 \\
(0-2.2)\end{array}$ & $\begin{array}{c}0.13 \\
(0-3)\end{array}$ & 31 & 36 & 24 & 9 \\
\hline 1994 & 426 & $\begin{array}{c}18 \\
(2-60)\end{array}$ & $\begin{array}{c}2.89 \\
(0.3-9.4)\end{array}$ & $\begin{array}{c}86 \\
(3-235)\end{array}$ & $\begin{array}{c}3.0 \\
(0-19.0)\end{array}$ & $\begin{array}{c}6.5 \\
(0.1-27.3)\end{array}$ & $\begin{array}{c}2.6 \\
(0.3-5.0)\end{array}$ & $\begin{array}{c}0.40 \\
(0-1.7)\end{array}$ & $\begin{array}{l}0.41 \\
(0-7)\end{array}$ & 27 & 20 & 49 & 5 \\
\hline 1996 & 507 & $\begin{array}{c}14 \\
(2-45)\end{array}$ & $\begin{array}{c}2.49 \\
(0.2-7.0)\end{array}$ & $\begin{array}{c}84 \\
(4-221)\end{array}$ & $\begin{array}{c}3.5 \\
(0-26.6)\end{array}$ & $\begin{array}{c}6.0 \\
(0.1-27.6)\end{array}$ & $\begin{array}{c}2.8 \\
(1-4.8)\end{array}$ & $\begin{array}{c}0.48 \\
(0-1.8)\end{array}$ & $\begin{array}{c}0.30 \\
(0-6)\end{array}$ & 34 & 25 & 34 & 7 \\
\hline 1997 & 468 & $\begin{array}{c}15 \\
(2-50)\end{array}$ & $\begin{array}{c}2.6 \\
(0.2-6.5)\end{array}$ & $\begin{array}{c}81 \\
(7-186)\end{array}$ & $\begin{array}{c}3.4 \\
(0-17.8)\end{array}$ & $\begin{array}{c}4.9 \\
(0.1-22.3)\end{array}$ & $\begin{array}{c}3.0 \\
(0.6-5.5)\end{array}$ & $\begin{array}{c}0.46 \\
(0-2.2)\end{array}$ & $\begin{array}{c}0.55 \\
(0-7)\end{array}$ & 35 & 38 & 15 & 12 \\
\hline
\end{tabular}


Table 3. Phocoena phocoena. Results of generalised additive models for the minimum adequate model (Model a) and for that with the inclusion of geographical co-ordinates (Model b). edf: estimated degrees of freedom

\begin{tabular}{|c|c|c|c|c|c|c|}
\hline & & & & & & \\
\hline & Estimate & SE & $\mathrm{p}$ & Estimate & SE & $\mathrm{p}$ \\
\hline Parametric coefficients & & & & & & \\
\hline Intercept & -1.8158 & 0.1490 & $<0.0001$ & -2.0958 & 0.1561 & $<0.0001$ \\
\hline Year & & & & & & \\
\hline Dummy1 & 1.5117 & 0.1661 & $<0.0001$ & 1.4325 & 0.1727 & $<0.0001$ \\
\hline Dummy2 & -0.420 & 0.1167 & $<0.0001$ & -0.4382 & 0.1241 & $<0.0001$ \\
\hline Dummy3 & 0.3873 & 0.1078 & $<0.0001$ & 0.4255 & 0.1137 & $<0.0001$ \\
\hline Sea state & & & & & & \\
\hline Dummy1 & -0.7196 & 0.0972 & $<0.0001$ & -0.6349 & 0.1027 & $<0.0001$ \\
\hline Dummy2 & -0.9147 & 0.1464 & $<0.0001$ & -0.7139 & 0.1525 & $<0.0001$ \\
\hline Dummy3 & -0.2890 & 0.2619 & ns & -0.2954 & 0.2646 & ns \\
\hline & edf & $\chi^{2}$ & $\mathrm{p}$ & edf & $\chi^{2}$ & $\mathrm{p}$ \\
\hline Approximate significan & smooth ter & & & & & \\
\hline s(Depth) & 3.687 & 57.70 & $<0.0001$ & 3.016 & 32.29 & $<0.0001$ \\
\hline s(Distance) & 3.420 & 28.41 & $<0.0001$ & 3.006 & 15.96 & $<0.005$ \\
\hline s(Tide height) & 2.910 & 36.79 & $<0.0001$ & 6.402 & 25.07 & $<0.005$ \\
\hline s(Stream speed) & 3.996 & 52.89 & $<0.0001$ & 0.857 & 11.85 & $<0.0001$ \\
\hline $\mathrm{s}($ Length $\times$ Speed $)$ & 5.844 & 42.83 & $<0.0001$ & 6.291 & 49.30 & $<0.0001$ \\
\hline $\mathrm{s}$ (Latitude $\times$ Longitude) & - & - & - & 22.941 & 221.1 & $<0.0001$ \\
\hline
\end{tabular}

\section{Predictions}

A second GAM on the complete dataset was fitted by including the coordinates of each survey segment as a bi-dimensional smoother (Model b in Table 3). The smoother was highly significant, while the effects of the other variables in the model showed similar levels of significance and displayed similar behaviour as in the original model (Table 3 and Fig. 3e-h). Statistical comparison between the models with and without coordinates was carried out using analysis of deviance; the inclusion of coordinates resulted in a significantly improved model $(\mathrm{p}<0.0001)$ which was now able to explain $38.5 \%$ of deviance (Table 4 ). This improved model was therefore chosen as the basis for further predictive analysis.

The predictive map of harbour porpoise distribution in the study area is presented in the centre of Fig. 4 and flanked by maps of the lower and upper extremes of the 'credible' interval as obtained from the simulation based on the prediction matrix, and explained above in the 'model fitting' section of 'Methods'. Geographically, the maps highlight the presence of 4 regions where the predicted relative abundance of harbour porpoise sightings is much higher than the average. These are (1) in the Sea of Hebrides, the region between Ardnamurchan Peninsula, Coll and the Small Isles; (2) the area at the southwest edge of the study region south of Barra; (3) in the North Minch, north of Skye up to Gairloch, and (4) between the Shiant Islands and the Pairc Peninsula, Isle of Lewis. Sightings are predicted to be very low in certain areas: mainly the areas further away from the coast in the very north and the very south of the study area, but also closer to shore off Benbecula and South Uist. The minimum predicted density is 0.01 sightings $\mathrm{km}^{-1}$, in these cases sightings are rare but nonetheless possible. The maps of the extremes of the credible prediction interval show the same locations to be of importance, but with lower and higher numbers of sightings predicted at any one location respectively.

To test if geographical predictions were significantly affected by variable segment size, a predictive map was made also using the sub-set with length-consistent segments discussed above and the position of the hotspots compared; exactly the same locations were identified as potential 'hotspots' in both maps.

Differences between years (Fig. 5) were investigated by comparing year-specific predictions. The model

Table 4. Comparison of deviance between Model a and Model b in Table 3

\begin{tabular}{|cccccc|}
\hline & Res. df & Res. dev. & df & Deviance & $p$ \\
\hline Model a & 1843.495 & 1746.47 & - & - & - \\
Model b & 1825.486 & 1524.03 & 18.009 & 222.43 & $<0.0001$ \\
\hline
\end{tabular}


First model
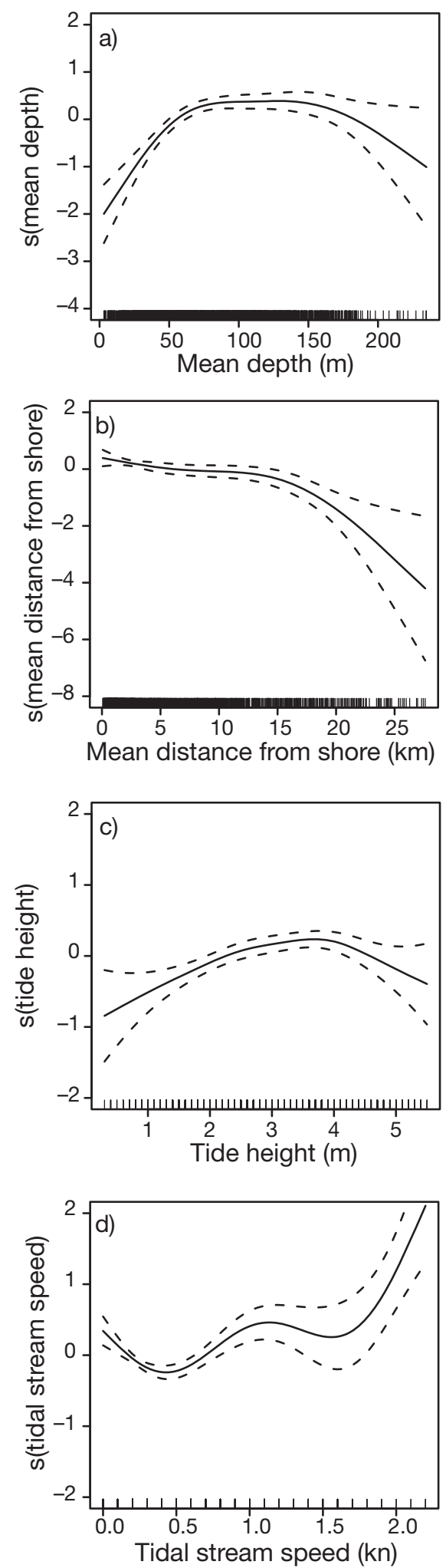

Second model
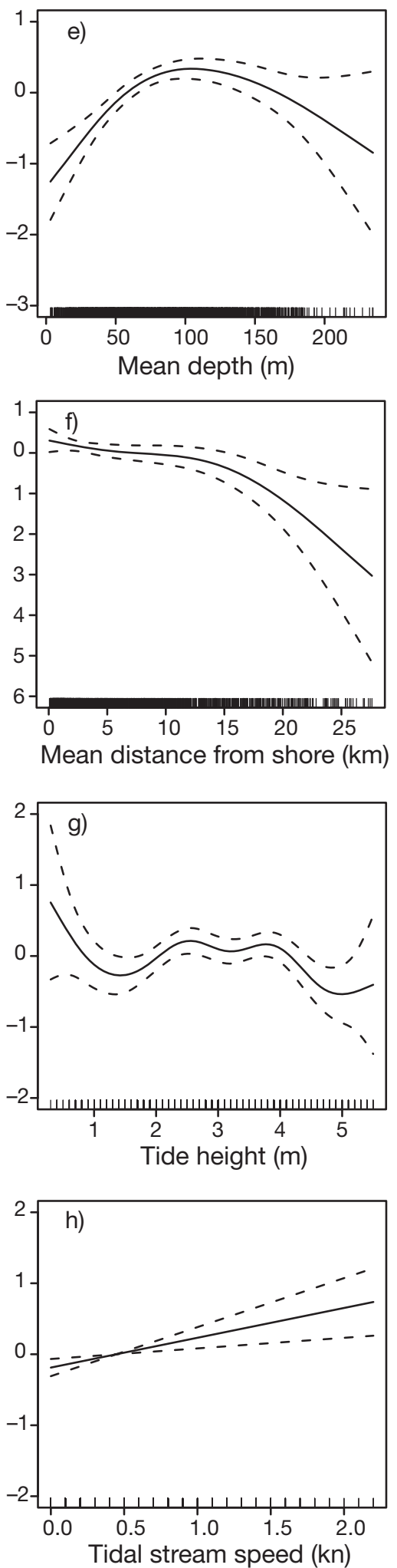

Fig. 3. Phocoena phocoena. (a-d) GAM results for the first minimum adequate model. (e-h) GAM results for the minimum adequate model that includes co-ordinates as a bi-dimensional smoother (second model). Plots show the results for the number of sightings per survey track as a function of the explanatory variables: $(a, e)$ depth, $(b, f)$ distance from shore, $(c, g)$ tide height and $(\mathrm{d}, \mathrm{h})$ tidal stream speed. Dotted lines represent $2 \mathrm{SE}$ ranges around the main effects. Vertical dashes on the $x$-axis represent the distribution of points in the model 


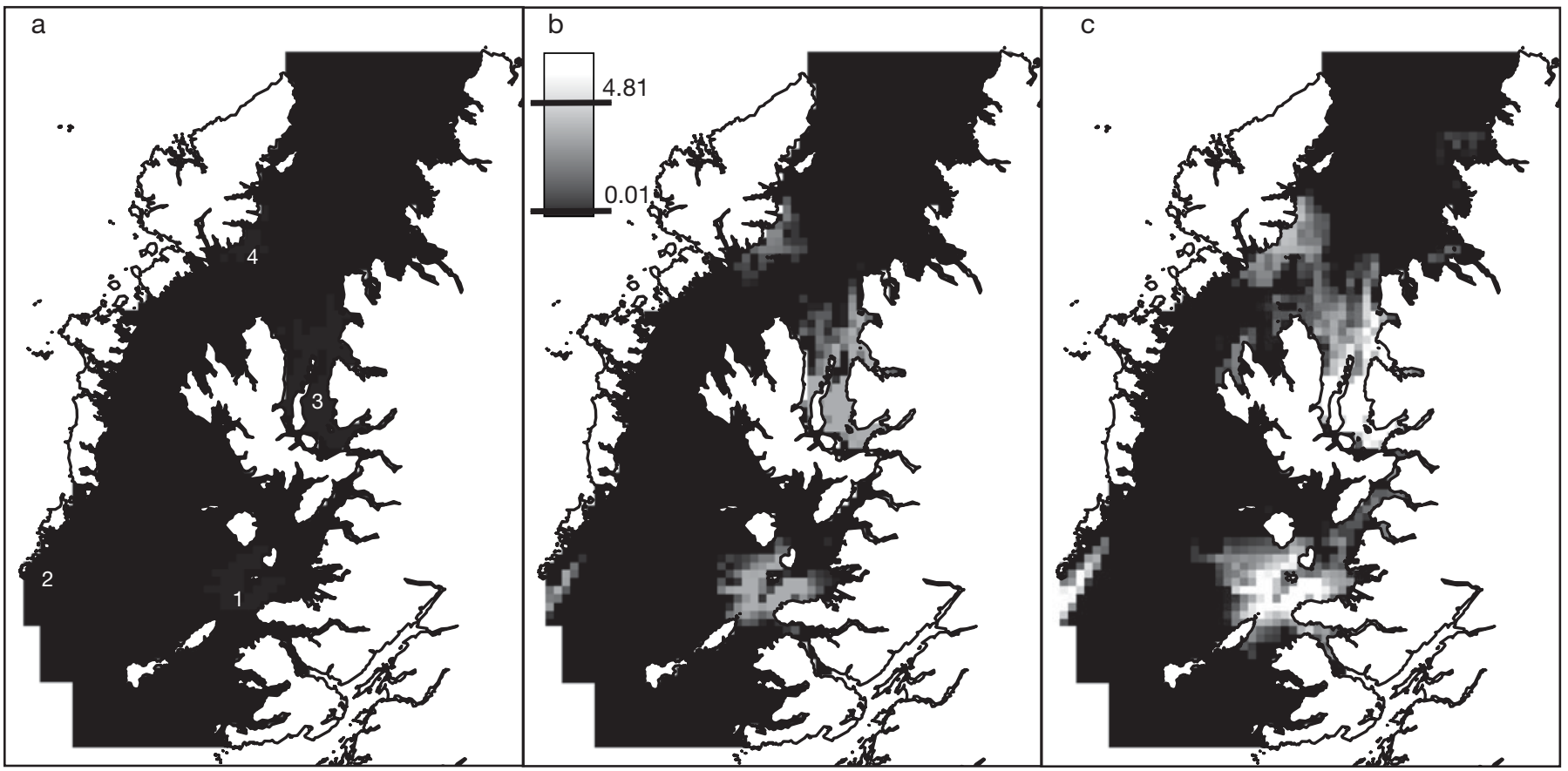

Fig. 4. Phocoena phocoena. Distribution of predicted sightings in the Greater Minch. Number of sightings was predicted at a $3 \times$ $3 \mathrm{~km}$ scale. Maps show the distribution of (a) lower extremes of credible intervals (2.5th percentile) of the predictions, (b) average predicted number of sightings and (c) upper extremes of credible intervals (97.5th percentile) of the predictions. A greyscale gradient with shades from pure black (number of sightings $=0$ ) to pure white (number of sightings $=7$ ) was used to code grid cells in all 3 maps; it is shown in (b) with lines across it to identify the shade of the minimum and maximum average predicted number of sightings. Predictions were made for a high neap tide with ideal sea conditions (Beaufort sea state $=0$ ) on the 11 August 1997. For clarity, the 4 areas of relative high abundance are marked only on (a): (1) the region between Ardnamurchan Peninsula, Coll and the Small Isles, (2) south of Barra, (3) north of Skye up to Gairloch and (4) between the Shiant Islands and the Pairc Peninsula, Isle of Lewis

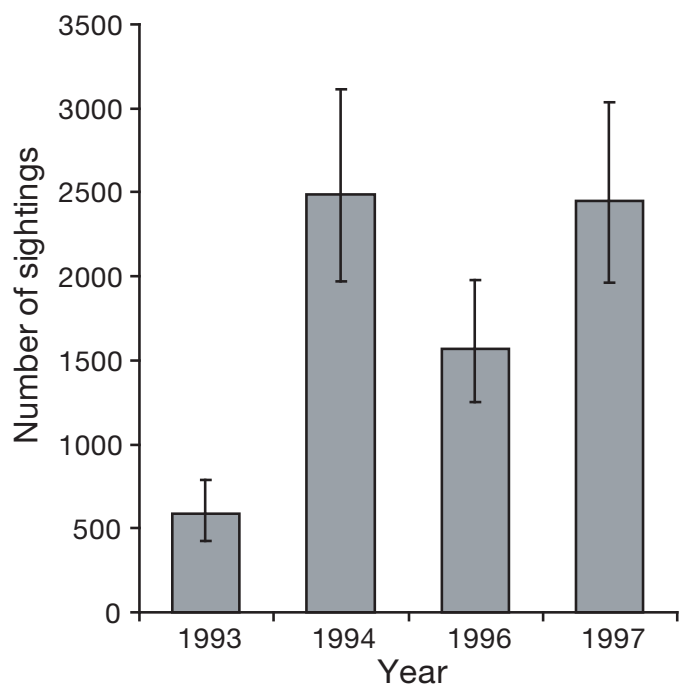

Fig. 5. Phocoena phocoena. Predicted number of sightings across the entire study area averaged for the years 1993, 1994, 1996 and 1997. Error bars show the credible interval, i.e. the 97.5 and 2.5 percentiles, obtained for each year. Predictions were made for a high neap tide with ideal sea conditions (Beaufort sea state $=0$ ) predicts a total of 2446 (95\% confidence interval (CI): 1962 to 3040) sightings of harbour porpoises for an ideal day in August 1997 over the whole study area. The factor 'year' was very significant in the model and this resulted in predictions between years varying from 584 (95\% CI: 426 to 789) sightings in 1993 to 2488 (95\% CI: 1967 to 3116 ) sightings in 1994, i.e. a 4 -fold change between consecutive years. If one considers that on average there were 1.88 individuals per sighting and that the study area covered $21222 \mathrm{~km}^{2}$, this resulted in a predicted average density of $0.05,0.22$, 0.14 and 0.22 ind. $\mathrm{km}^{-2}$ on an ideal day in August 1993, 1994, 1996 and 1997, respectively.

Conscious of the fact that not exactly all areas were surveyed in each year, we also tested the model and its prediction of the difference in relative abundance between years on a geographically consistent sub-set of segments. This sub-set included only those segments belonging to any $10 \mathrm{~km}^{2}$ grid cell that was surveyed consistently each year; in total 1045 segments were included (1993: 255; 1994: 208; 1996: 283; 1997 : 299). Predicted differences between years were just as highly significant with this sub-set as with the com- 
plete dataset; sighting numbers were lowest in 1993, highest in 1994 and 1997 and intermediate in 1996.

\section{DISCUSSION}

This study has developed a predictive habitat model for harbour porpoises in the Minches and Sea of Hebrides. This very diverse and productive sea area to the west of Scotland is characterised by a highly complex topography; the jagged coastline comprises a series of fjordic sea lochs and the relationship between depth and distance from shore varies greatly. Nonetheless, the model has highlighted significant relationships between topographical variables and the distribution of harbour porpoises, which are consistent with previous findings. In particular, MacLeod et al. (2007) in a habitat study from the West of Scotland (including the Minches but stretching far off the continental shelf west of the Outer Hebrides), found that harbour porpoises were preferentially recorded in waters closer than $15 \mathrm{~km}$ from the coast and deeper than $60 \mathrm{~m}$. This compares closely with the present findings of a preference for water closer than $15 \mathrm{~km}$ from the shore and at a depth greater than $50 \mathrm{~m}$ but shallower than $150 \mathrm{~m}$. Goodwin \& Speerdie (2008) also reported on a positive relationship between sightings of porpoises and depth between 50 and $100 \mathrm{~m}$.

The model was significantly improved by the inclusion of geographical coordinates. In some studies, latitude or longitude are included and used as proxies for ecological variables that could not be measured, such as primary productivity or temperature. The complex topography and hydrography of the Minches limits the possibility of identifying such a proxy. Salinity and density increase from east to west, mainly due to the higher freshwater input off the mainland (Gillibrand et al. 2003), but the difference is minimal in summer. Surface primary production appears also to be somewhat related to longitude as the seasonal bloom tends to start earlier near the mainland. However, the co-ordinates are fitted in the model with a bi-dimensional smoother and their influence is highly non-linear; thus, whatever combination of ecological variables for which the co-ordinates might be a proxy, it is not expected to show a linear relationship with either latitude or longitude per se.

Inclusion of geographical co-ordinates has the undesirable consequence that the model cannot be extended beyond the boundaries of the study area. However, the predictions of the original minimum adequate GAM (excluding geographical co-ordinates) could be tested elsewhere to see whether the environmental relationships determined here reflect porpoise habitat requirements in other areas.
Furthermore, the model provides evidence for a relationship between tidal variables and porpoise distribution. Tidal height and stream speed vary spatially as well as temporally (diurnal and monthly) and these 2 components cannot be distinguished a priori in this analysis where tidal current and height were calculated for each survey segment. Thus, at the scale of the entire study region, the model predicts an overall higher number of sightings during high tide than during low tide; equally, at any time, higher numbers of sightings are predicted for areas with higher stream speeds. However, some inference can be made of the extent to which the spatial component plays a role relative to the temporal component by comparing the models with and without the inclusion of the geographical co-ordinates. Both variables are highly significant in the first GAM model, and the inclusion of the co-ordinates only succeeds to lessen the significance of tide height to some degree. We would have expected tidal variables to drop out of the second GAM if their spatial component was of much greater importance then their temporal component. Movements associated with tides are commonly documented in small cetaceans and are likely to reflect changes in prey distribution (Gaskin \& Watson 1985, Borges \& Evans 1997, Mendes et al. 2002, Santos \& Pierce 2003, Johnston et al. 2005). In addition, considering the large size of this area $\left(>20000 \mathrm{~km}^{2}\right)$, it seems unlikely that these changes are due exclusively to movement of harbour porpoises into and out of the area. Instead, we propose another mechanism whereby changes in the tidal regime influence the behaviour of harbour porpoises at the surface and that this in turn affects the capacity of the human observer to spot them. They might for example be foraging rather than travelling and these different activities are likely to differ in the manner and rate with which individuals are present at the surface and therefore potentially detected.

To what degree this model is representative of porpoise habitat preferences throughout the year is open to debate; especially if habitat preferences are linked to prey availability some changes might be encountered as seasonal variations in diet are likely (Santos et al. 2004). August and September have been proposed as the months with peak numbers of porpoise encounters in this as well as in other coastal regions off Scotland (Evans et al. 2003, Weir et al. 2007). Seasonal migrations in this species have also been documented in other geographical areas such as the German Baltic Sea (Siebert et al. 2006, Verfuß et al. 2007) and the northwest Atlantic where there is an overall tendency for increased use of coastal areas during the summer months (Read 1999). Unfortunately, no ad hoc survey has yet been conducted to address seasonality patterns in relation to the northwest of Scotland, and available 
datasets are biased by much greater survey effort in summer.

Having identified a set of important habitat variables, the next step in this study was to develop predictions of the distribution patterns throughout the study area. One technique to provide predictive maps is to divide available data into 2 sub-sets; one to be used for developing the model and a second one to be used to test the accuracy of the model. While this is a valid approach which provides a tangible test of the significance of the predictions, it reduces the number of data points in the original model. Also, in census studies, observations are often correlated and, therefore, because of the lower effective sample size, this technique might not be as powerful as one would expect for uncorrelated data. Instead, we implemented model selection and cross-validation as suggested by Wood \& Augustin (2002) and Wood (2006).

It is widely known that species-habitat relationships are scale-dependent, as patterns of covariates are likely to change with a change in resolution (e.g. Wiens 1989, Schneider 1994, Ballance et al. 2006). Recognising this, we have tried to match the resolution of the predictions and that of analysis as closely as possible and chose to adopt the most common resolution (average segment size) at which data were observed. While we acknowledge that this could theoretically cause some mismatch, in practice we tested the model and predictions on size consistent sub-set of the data and having obtained the same results, we are confident of the robustness of these analyses.

Overall, the model predicts the distribution of harbour porpoises to be preferentially concentrated around 4 main regions. In the Sea of Hebrides, the regions between Ardnamurchan, Coll and the Small Isles appear as high frequency areas in the model. Important sandeel habitats have been identified within this highlighted region off Ardnamurchan, and minke whales which are known to favour this prey species when available have shown a preference for this area (Macleod et al. 2004). In contrast, a direct match between the spatial distribution of harbour porpoises across the whole study area and that of the lesser sandeel Ammodytes marinus appears unlikely (Wright \& Reeves 1994, Frederiksen et al. 2005). This finding agrees with the observation by Santos et al. (2004) that sandeels, which make up the bulk of the diet of harbour porpoises on the east coast, are a much less important prey on the west coast of Scotland where whiting and other gadoids (particularly Trisopterus spp.) are the most common prey categories in stomach contents of stranded harbour porpoises. It is of interest that increased predicted sightings occur also south of Barra. Harbour porpoises have been sighted further west of the Outer Hebrides to the shelf edge (Macleod et al. 2003, MacLeod et al. 2007); this might indicate a preference to use this area between Mingulay and Barra when entering the Sea of Hebrides, maybe as part of a seasonal pattern of movement.

In the north of our study area, high numbers of sightings of harbour porpoise are predicted north of Skye to Gairloch on the east and off Piarc Peninsula to Shiant Islands on the west. Whatever the mapped percentile of the credible interval chosen, the location of the centre of the 2 areas with higher porpoise relative abundance does not vary, but the degree of separation between these 2 centres does. In the extreme case of the upper limit of the $97.5 \%$ interval, the 2 areas were shown to merge into a very large one.

Although we have highlighted these areas of higher density, it is also important to point out that porpoises tend to be present everywhere; indeed no single area has zero predicted sightings. This is not surprising in a wide-ranging species such as the harbour porpoise whose range and seasonal migrations are expected to be much larger than the extent of the present study region. In the Bay of Fundy, Johnston et al. (2005) followed the fine-scale movements of harbour porpoises using telemetry; they found that each individual exhibited a core-use area of limited size (about $300 \mathrm{~km}^{2}$ ) surrounded by a much larger region (ca. $9000 \mathrm{~km}^{2}$ ) visited only occasionally within a month. In addition, they were able to show that core-use areas coincided with predictable fine-scale oceanographic features that aggregate prey. We suggest that also in the Minches and Sea of Hebrides, areas of higher relative abundance correspond to areas of favourable habitat and most reliable feeding opportunities but, as porpoises move between these geographically distinct areas, they cross less suitable habitats, hence their presence may be recorded throughout.

Our findings have important implications in conservation terms. The identification of high-use areas might suggest areas where to concentrate conservation efforts for this species, such as monitoring potential pressures (by-catch rates, noise pollution); at the same time, the finding that individuals may be encountered throughout the study area should act as a warning against limiting conservation efforts within a spatial scale that is likely to be much smaller than an individual's monthly foraging movements. Indeed, this study highlights the urgent need to understand the extent of individual porpoise movements in UK waters, so successfully done for example through telemetry studies in Canada (Johnston et al. 2005); only when the degree of connectivity between high-use areas is better understood, can meaningful decisions on the extent of spatial protection be carried out.

The model was also used to compare harbour porpoise abundance between years. Significant differ- 
ences were found between consecutive years, and 1993 in particular had only a third of the average estimate. Similarly, Cañadas \& Hammond (2006) found 4-fold changes in abundance for bottlenose dolphins off the Mediterranean coast of Spain over several years. Their detailed knowledge of individuals allowed these authors to interpret these changes as fluctuations due to immigration and emigration. Inter-annual fluctuations in harbour porpoise sighting rates have been observed also off the coast of California; in this case, fluctuations were assumed to be related to inter-annual variability in sea-surface temperature (Forney 1999).

While natural fluctuations can be expected in a longterm dataset, their extent must be a function of the size of the study area relative to the effective range of the population observed. In the northeast Atlantic, harbour porpoises from the French coast of the Bay of Biscay to the Norwegian and Icelandic coasts appear to consist of a single more or less continuous population with no obvious ecological barrier to limit their dispersal, genetic isolation occurring primarily by distance (Fontaine et al. 2007). Nonetheless, mating does not occur randomly over the whole area and some genetic differentiation has been reported between different regional seas (Tiedemann 1996, Andersen et al. 1997, Walton 1997). Thus, we assume that the present study region represents only a small part of the effective range of the observed porpoises, and the large interannual fluctuations observed reflect movements in and out of the region. Indeed, a comparison of abundance estimates between SCANS I \& II showed no change in the total number of harbour porpoises in the North Sea and adjacent areas (1994: 341 000; 2005: 335000$)$ but large differences in their geographical distribution with an increased concentration of individuals in the southern North Sea and English Channel during July 2005 compared to July 1994 (Hammond \& Macleod 2006). To estimate trends and make inferences on conservation and management, it is crucial to monitor the number of porpoises at the appropriate geographical scale that has direct relevance to the population (as for example with SCANS); conversely, this study shows that when the geographical scale is much smaller than the range used by a population, the number of sightings observed can be expected to fluctuate to a high enough degree to hide any actual trend in population size; thus, monitoring programmes on this scale are unlikely to succeed in assessing conservation status.

Acknowledgements. This analysis was carried out while F.M. was a Daphne Jackson Fellow sponsored by the National Environmental Research Council. Thanks to S. Mendes and E. Pinn for valuable comments on earlier versions of the manuscript. P.G.H.E. acknowledges grant aid from Earthwatch Europe, logistical support from C. Swann who provided and skippered the 'Marguerite Explorer', and its crew and the many Sea Watch volunteers that helped with our surveys. G.J.P. acknowledges support from the EU-funded EnviEFH (FP6-2004-SSP-4-02246) and ANIMATE (MEXC-CT-2006042337) projects. We acknowledge the help of P. Anderwald, M.E. Baines, M. Reichelt, J. Wang, C. Macleod, and S. Bannon. Thanks also to the anonymous referees who helped us improve the manuscript through their constructive comments.

\section{LITERATURE CITED}

Akaike H (1973) Information theory and an extension of the maximum likelihood principle. In: Petrov BN, Csake F (eds) Proc 2nd International Symposium on Information Theory. Akademiai Kiado, Budapest, p 267-281

Andersen LW, Holm LE, Siegismund HR, Clausen B, Kinze CC, Loeschcke V (1997) A combined DNA-microsatellite and isozyme analysis of the population structure of the harbour porpoise in Danish waters and West Greenland. Heredity 78:270-276

Andersen LW, Ruzzante DE, Walton M, Berggren P, Bjørge A, Lockyer C (2001) Conservation genetics of the harbour porpoise, Phocoena phocoena, in eastern and central North Atlantic. Conserv Genet 2:309-324

ASCOBANS (2000) Proceedings of the third meeting of parties to ASCOBANS. Bristol, UK. 26-28 July 2000. Available at www.service-board.de/ascobans_neu/files/ MoP3FindalReport.pdf

Ballance LT, Pitman RL, Fiedler PC (2006) Oceanographic influences on seabirds and cetaceans of the eastern tropical Pacific: a review. Prog Oceanogr 69:360-390

Barne JH, Robson CF, Kaznowska SS, Doody JP, Davidson NC, Buck AL (1997) Coasts and Seas of the United Kingdom. Regions 15 \& 16. Northwest Scotland: the Western Isles and West Highland. Joint Nature Conservation Committee, Peterborough

Borges L, Evans PGH (1997) Spatial distribution of the harbour porpoise and fish prey and their associations in southeast Shetland, Scotland. In: Evans PGH (ed) European research on cetaceans, vol 10. European Cetacean Society, Kiel, p 262-265

Cañadas A, Hammond PS (2006) Model-based abundance estimates for bottlenose dolphins off southern Spain: implications for conservation and management. J Cetacean Res Manag 8:13-27

> Craven P, Wahba G (1979) Smoothing noisy data with spline functions. Numer Math 31:377-403

Defra (2006) A marine bill. A consultation document. Defra, London.

Embling CB (2007) Predictive models of cetacean distributions off the west coast of Scotland. PhD thesis, University of St Andrews

Evans PGH (1980) Cetaceans in British Waters. Mammal Rev 10:1-52

Evans PGH (1997) Whales, dolphins and porpoises. In: Barne JH, Robson CF, Kaznowska SS, Doody JP, Davidson NC, Buck AL (eds) Coasts and Seas of the United Kingdom. Regions 15 \& 16. Northwest Scotland: the Western Isles and West Highland. Joint Nature Conservation Committee, Peterborough, p 162-167

> Evans PGH, Hammond PS (2004) Monitoring cetaceans in European waters. Mammal Rev 34:131-156

Evans PGH, Wang J 2002 Re-examination of distribution data for the harbour porpoise around Wales and the UK with a view to site selection for this species. Sea Watch Foundation, Oxford

Evans PGH, Anderwald P, Baines ME (2003) UK cetacean sta- 
tus review. Report to English Nature and Countryside Council for Wales. Sea Watch Foundation, Oxford

Fontaine MC, Baird SJE, Piry S, Ray N and others (2007) Rise of oceanographic barriers in continuous populations of a cetacean: the genetic structure of harbour porpoises in Old World waters. BMC Biol 5:30

Forney KA (1999) Trends in harbour porpoise abundance off central California, 1986-95: Evidence for inter-annual changes in distribution? J Cetacean Res Manag 1:73-80

Frederiksen M, Wright PJ, Harris MP, Mavor RA, Heubeck M, Wanless S (2005) Regional patterns of kittiwake Rissa tridactyla breeding success are related to variability in sandeel recruitment. Mar Ecol Prog Ser 300:201-211

Gaskin DE, Watson AP (1985) The harbour porpoise, Phocoena phocoena, in Fish Harbour, New Brunswick, Canada: Occupancy, distribution, and movements. Fish Bull 83:427-442

Gillibrand PA, Sammes PJ, Slesser G, Adams RD (2003) Seasonal water column characteristics in the Little and North Minch and the Sea of the Hebrides. I. Physical and chemical parameters. Fisheries Research Services Internal Report No. 08/03. Available at: www.frs-scotland.gov.uk/ FRS.web/Uploads/Documents/0803INT.pdf

Goodwin L, Speedie C (2008) Relative abundance, density and distribution of the harbour porpoise (Phocoena phocoena) along the west coast of the UK. J Mar Biol Assoc UK 88:1221-1228

Hammond PS, Macleod K (2006) Progress report on the SCAN II project. Paper prepared for the 13th Advisory Committee to ASCOBANS, Tampere, Finland, 25-27 April

Hammond PS, Berggren P, Benke H, Borchers DL and others (2002) Abundance of harbour porpoise and other cetaceans in the North Sea and adjacent waters. J Appl Ecol 39:361-376

Hastie TJ, Tibshirani RJ (1990) Generalized additive models. Chapman and Hall, London

> Johnston DW, Westgate AJ, Read AJ (2005) Effects of finescale oceanographic features on the distribution and movements of harbour porpoises Phocoena phocoena in the Bay of Fundy. Mar Ecol Prog Ser 295:279-293

> Macleod K, Simmonds MP, Murray E (2003) Summer distribution and relative abundance of cetacean populations off northwest Scotland. J Mar Biol Assoc UK 83:1187-1192

Macleod K, Fairbairns R, Gill A, Fairbairns B, Gordon J, BlairMyers C, Parsons ECM (2004) Seasonal distribution of minke whales Balaenoptera acutorostrata in relation to physiography and prey off the Isle of Mull, Scotland. Mar Ecol Prog Ser 277:263-274

MacLeod CD, Weir CR, Pierpoint C, Harland EJ (2007) The habitat preferences of marine mammals west of Scotland (UK). J Mar Biol Assoc UK 87:157-164

Marubini F, Davies PS (1996) Nitrate increases zooxanthellae population density and reduces skeletogenesis in corals. Mar Biol 127:319-328

Mendes S, Turrell W, Lütkebohle T, Thompson P (2002) Influence of the tidal cycle and a tidal intrusion front on the spatio-temporal distribution of coastal bottlenose dolphins. Mar Ecol Prog Ser 239:221-229

Northridge S, Sanderson JD, Mackay AI, Hammond PS (2003) Analysis and mitigation of cetacean by-catch in UK fisheries. Final report to the Department of Environment, Food and Rural Affairs (DEFRA), project MF0726. DEFRA, London

Palka D (1996) Effects of Beaufort sea state on the sightability of harbour porpoises in the Gulf of Maine. Rep Int Whaling Comm 46:575-582

Parsons ECM, Shrimpton J, Evans PGH (1999) Cetacean con- servation in northwest Scotland: perceived threats to cetaceans. European Research on Cetaceans. Vol 13. European Cetacean Society, Cambridge

Read AJ (1999) Harbour porpoise Phocoena phocoena (Linnaeus 1758). In: Ridgway SH, Harrison SR (eds) Handbook of marine mammals Vol 6: The second book of dolphins and porpoises. Academic Press, San Diego, CA, p 323-356

Redfern JV, Ferguson MC, Becker EA, Hyrenbach KD and others (2006) Techniques for cetacean-habitat modelling. Mar Ecol Prog Ser 310:271-295

Reid JB, Evans PGH, Northridge SP (2003) Atlas of cetacean distribution in north-west European waters. Joint Nature Conservation Committee, Peterborough

Santos MB, Pierce GJ (2003) The diet of harbour porpoise (Phocoena phocoena) in the Northeast Atlantic. Oceanogr Mar Biol Ann Rev 41: 355-390

Santos MB, Pierce GJ, Learmouth JA, Reid RJ and others (2004) Variability in the diet of harbor porpoises (Phocoena phocoena) in Scottish waters 1992-2003. Mar Mamm Sci 20:1-27

Schneider DC 1994. Quantitative ecology. Spatial and temporal scaling. Academic Press, San Diego, CA

Scottish Executive (2007) Scottish marine renewables strategic environmental assessment (SEA). Faber Maunsell and Metoc, Edinbourgh

Siebert U, Gilles A, Lucke K, Ludwig M, Benke H, Kock KH, Scheidat M (2006) A decade of harbour porpoise occurrence in German waters - analyses of aerial surveys, incidental sightings and strandings. J Sea Res 56:65-80

Swartzman G, Huang C, Kaluzny S (1992) Spatial analysis of Bering Sea groundfish survey data using generalized additive models. Can J Fish Aquat Sci 49:1366-1378

Tiedemann R (1996) Mitochondrial DNA sequence patterns of harbour porpoises (Phocoena phocoena) from the North and the Baltic Sea. Z Saugetierkd 61:104-111

> Tolley KA, Vikingsson G, Rosel P (2001) Mitochondrial DNA sequence variation and phylogeographic patterns in harbour porpoises (Phocoena phocoena) from the North Atlantic. Conserv Genet 2:349-361

> Verfuß UK, Honnef CG, Meding A, Dähne M, Mundry R, Benke H (2007) Geographical and seasonal variation of harbour porpoise (Phocoena phocoena) presence in the German Baltic Sea revealed by passive acoustic monitoring. J Mar Biol Assoc UK 87:165-176

$>$ Walter SD, Feinstein AR, Wells CK (1987) Coding ordinal independent variables in multiple regression analyses. Am J Epidemiol 125:319-323

> Walton MJ (1997) Population structure of harbour porpoises Phocoena phocoena in the seas around the UK and adjacent waters. Proc R Soc Lond B Biol Sci 264:89-94

Weir CR, Stockin KA, Pierce GJ (2007) Spatial and temporal trends in the distribution of harbour porpoises, whitebeaked dolphins and minke whales off Aberdeenshire (UK), north-western North Sea. J Mar Biol Assoc UK 87:327-338

Wiens J (1989) Spatial scaling in ecology. Funct Ecol 3: 385-397

Wood S (2006) Generalized Additive Models: an introduction with R. Chapman \& Hall, Boca Raton, FL

Wood SN, Augustin NH (2002) GAMs with integrated model selection using penalized regression splines and applications to environmental modelling. Ecol Modell 157:157-177

Wright PJ, Reeves SA (1994) Sandeel availability to salmonids in Scottish waters. In: Problems with sea trout and salmon in the Western Highlands. In: MacKenzie DJ, Shelton RGJ (eds) Atlantic Salmon Trust, Pitlochry, p 42-47

Zar JH (1984) Biostatistical analysis, 2nd edn. Prentice-Hall, Upper Saddle River, NJ 